\title{
Erratum to: Multi-Criteria Decision Making to Measure Quality of Life: An Integrated Approach for Implementation in the Urban Area of Thessaloniki, Greece
}

\author{
A.-M. Feneri • D. Vagiona • N. Karanikolas
}

Published online: 27 January 2015

(C) Springer Science+Business Media Dordrecht and The International Society for Quality-of-Life Studies (ISQOLS) 2015

\section{Erratum to: Applied Research Quality Life (2014) DOI 10.1007/s11482-014-9335-1}

Unfortunately, the Acknowledgment section was missing in the article. The Acknowledgment is given below.

\section{Acknowledgments}

The research was co-funded by the Act 'S.S.F Scholarships Program-IKY' for first cycle's Master studies, through the Operational Program "Education and Lifelong Learning", of the European Social Fund (ESF) and Greek National Funds (NSRF) 2007-2013.

The online version of the original article can be found at http://dx.doi.org/10.1007/s11482-014-9335-1.

A.-M. Feneri $(\bowtie) \cdot$ D. Vagiona $\cdot$ N. Karanikolas

Department of Spatial Planning and Development School of Engineering,

Aristotle University of Thessaloniki, Thessaloniki, Greece

e-mail: amari.fen@gmail.com 